\title{
Uncertainty under Climate Change: the Resource Cycle of Industry in Taiwan's Offshore Islands
}

\author{
Yu-Hsuan Lan ${ }^{1}$ Chang-Hsien $\mathrm{Hsu}^{1 *}$ \\ ${ }^{1}$ Department of Business Administration, Asia University, Taiwan
}

\begin{abstract}
The annual rainfall in Taiwan is actually 2.6 times than the average number in the world. There are as many as $2,500 \mathrm{~mm}$ of rainfall per year, but because of the geographical and climatic conditions, which leads to the fact that even if the rainfall is abundant in Taiwan, the water consumption of the people living in the island area is really far below the global average. A large part of the rainfall follows violent rain caused by the deterioration of the environment. The delay of the rainy season and the increase of the intensity of the typhoon have caused to suffer from flooding every year in Taiwan. This study takes "WIND LION PLAZA " as the object. How do private enterprises "Kinmen" in the offshore islands where resources are more scarce implement "water saving measures and resource reuse" promoted by the government? In addition, it also includes the purpose and expectation of the implementation of this policy by the enterprise. Furthermore, how to implement the resource cycle and the management level between the government and the enterprise is to achieve sustainable development of resources, and do corporate social responsibility to achieve sustainable development of resources.
\end{abstract}

\section{Introduction}

The rise of global greenhouse gas concentrations can be traced back to the 1970s and from that moment, many countries have paid more and more attention to the specific issues related to energy conservation and resource reuse. Moreover, these countries have also signed conventions at relevant UN conferences, including The United Nations Framework Convention on Climate Change, which was adopted on May 9th, 1992, and the Earth Summit in Rio de Janeiro, Brazil, in June of the same year. The convention was signed by 155 countries to support the related measures of climate change. .

In 1997, the "Kyoto Protocol" was formulated with the goal of controlling the amount of greenhouse gases in the atmosphere and maintaining it at an appropriate level to prevent further serious damage to humans." In the past decades, it is not difficult to find that the ice layers of the Antarctic and the Arctic are melting, and as the sea level rises year by years, the atmosphere and ocean loss balance, the typhoon and the intensity of drought occur are higher[1]. Experts and scholars from all over the world are trying to slow down and solve the problem of global climate change in various ways. Facing environmental protection, perseverance and circulation, it has become a problem and topic that has received considerable attention and endowment.

From the above, we can understand, in recent years, the attitudes of domestic government and enterprises on environmental issues are particularly important. Facing extreme global climate anomalies, in addition to actively promoting resource recycling and sustainable use of resources by government agencies, on the other hand, we need the cooperation and support of local enterprises, and actively promote the determination of sustainable use of resources to save energy and reduce carbon emissions, greenhouse gas emissions, and protect the environment and sustainable circulation. In Taiwan, it is different from other countries that up to $90 \%$ of our energy must rely on overseas support. Jinmen County, which is located on the outlying islands, is not only lacking more lakes, long rivers, but also lacking fresh water easily. Resources make it more important and immediate in the recycling of water resources and the sustainable use of resources.

From 2008 to 2017, according to the annual rainfall records of the Meteorological Bureau in Kinmen, there is not much record of annual rainfall exceeding one thousand millimeters in Jinmen County. Under the condition of lack of rain, climate warming, the evaporation larger than the rainfall, it highlights the inadequacy of the innate conditions of Jinmen water resources[2]. In other words, the "resource cycle" is already an inevitable important issue or solutions. The promotion and development of sustainable resources development by the government and enterprises is just about time. Therefore, this study takes "sustainable resource development" as the topic, and bases on how the company implements "resource reuse" in accordance with corporate responsibility, to explore the implementation of relevant issues, in order to how much "remediation" can be given to the environment while understanding the company's promotion of related issues and In practice,

* Corresponding author:kosunstar@gmail.com 


\section{Water resources and sustainable Development}

Water resources is one of the most important impact mechanisms for global sustainable development including Agenda 21, which was proposed by the United Nations Environment and Development Agency in 1992. At that time, sustainable water resources development was listed as an important issue for future development of the whole world. Proposing the Plan for Sustainable Development of Water Resources, which also pointed out the importance of "protection of water quality and supply".

And the United Nations Council for Sustainable Development also proposed three aspects of water resources in the recommendations for sustainable development indicators, including environmental aspects, protecting and promoting human health and water resources. In addition, in the OECD's environmental indicators, it also proposed several indicators for sustainable water resources development, such as legally allowed water intake and dry season effective rainfall throughout the year. The amount of low-flow rivers caused by water intake and the daily supply and demand of water in various places.

As related policies for domestic water resources-, it mentioned in the Sustainable Development Forum that industrial development must take into account water resources, water price and water rights policies. Its application must also be coordinated with social development, and how to allocate water to save water; The BCSD-Taiwan which was established in 1997 is mainly a combination of more than 30 large enterprises in China and a member of the WBCSD Global Alliance(World Business Council for Sustainable Development). It also cooperated with international development trends like policy decrees, education and training, environmental management, resource protection, ecological conservation, pollution prevention and control. Such project research in various fields will promote the sustainable development of enterprises in Taiwan.

Therefore, how to truly implement sustainable development and resource sustainability is a common problem faced by all countries. In other words, the deterioration of global environmental quality caused by non-sustainable economic development, such as freshwater, forest, topsoil and marine fish of renewable resources. In the past decades, those has been rapidly reducing and deteriorating. Responding to those issues such as water resources, energy, health, poverty eradication, agricultural resources, and biodiversity, the United Nations also held the "Earth Summit" in Johannesburg, South Africa in 2002. In the summit, we discussed the issues such as promoting sustainable development under the trend of globalization, and hoped that we can truly implement sustainable development.

\section{Corporate social responsibility of Taiwanese}

Under the influence of globalization, enterprises have certain influenced and impact on the country's economic direction, environmental and environmental awareness, labor rights and human rights, and the people's globalization of the enterprise is expanding. The voice of social responsibility was also more normal. In this atmosphere, corporate social responsibility was gradually receiving the attention and expectation of the global society. Compared with the East, Western society pays more attention. In this regard, Taiwan began to advocate CSR plans to be traced back to 2000 by government units in conjunction with private enterprises, including promoting the strengthening of domestic enterprises on the relevant areas of corporate social responsibility, introducing international agreements and provisions, holding international conferences and In the same year, in October of the same year, "World Magazine" announced "21st Century New Standard Enterprise", which included corporate citizenship responsibility, social welfare activities, social welfare excellence, cross-border International operational capability and benchmarking companies in various industries, and this has become the first mechanism in China to conduct CSR surveys and evaluations with civil society.

2005, The Ministry of Economic Affairs has also commissioned the Taiwan Asia Foundation to implement the "CSR Case Analysis Project for Taiwanese Enterprises' Overseas Investment", which is also the first time that an official institution conducts research on Taiwan's multinational CSR; "Vision Magazine" has undergone five consecutive years of CSR related research and research. In fact, in the past ten years of implementing CSR in Taiwan, in fact, it was able to have positive feedback and influence on the enterprise itself. At the same time, for the people, the corporate image and goodwill of the enterprise were even. There was a certain correlation to the brand value of the company. However, compared with the positive impact that CSR brings to enterprises, in the process of promotion, it will be found that the cost is considerable. Moreover, it is impossible to verify whether the company has a significant effect in a short period of time. Under such circumstances, many companies will also make progress.

Actually, how to find their own benefit assessment model, is The challenge of all enterprises is, in the end, that CSR must be reflected in all employees. Propaganda and practice cannot cause "level gaps" and avoid moving only among senior executives. These four major items are the immediate improvement of Taiwanese companies in implementing CSR. The part, and how to further pass the CSR to make the enterprise truly give back or implement the implementation, whether it is more 
common on the relevant issues and the government's support or not.

\section{Implementation}

As for the implementation part,in Taiwan, because of the geographical location, the damage caused by typhoons and earthquakes every year makes the cost of repairing disasters much higher than that of other countries. Furthermore, due to topographical factors, the average annual average more than 2,000 also flows into the sea quickly. In addition, the uneven seasonal distribution and the insufficient reservoir storage capacity makes the water consumption of the people living in the island area is far below the global average."WIND LION PLAZA " is the first large shopping mall in Kinmen County. Compared to Taiwan, Jinmen County is an outlying island rare in natural resources. The biggest challenge is the Insufficient supply of water resources, and for this part, "WIND LION PLAZA " has also been greatly improved through self-powered solar power and water recycling systems, as shown below :

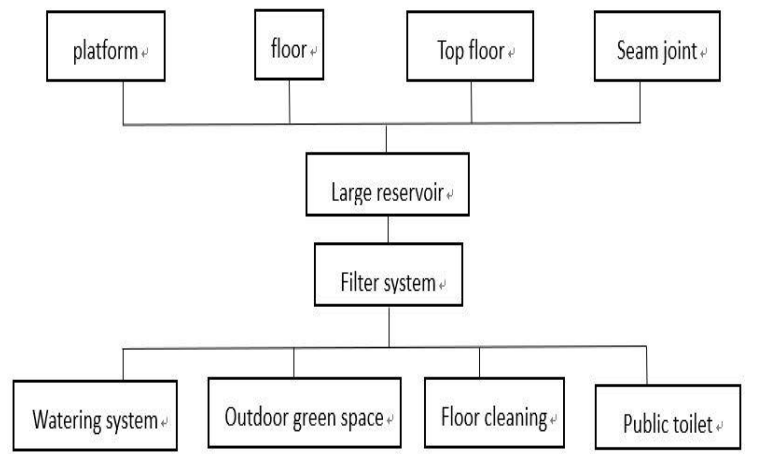

Fig 1. The system of water resource recycling

According to Figure 1, it can be clearly understood that the "WIND LION PLAZA " uses the water utilization system to completely use the rainwater. The pipelines are hidden in the platform, floor, top floor and joints of the building. When it rains, it flows into the large reservoir through the pipelines. The water storage tank is purified and applied to all levels of the building and the reuse rate reaches $100 \%$. Furthermore, the water-saving facilities and the cloud monitoring system are combined to effectively reduce the running water consumption by about $40 \%$. As for the solar power generation, the plaza has a total of 759 solar panels, with a total power generation area of $1239.8265 \mathrm{~m} 2$. Since 2014 , it has produced 830,000 $\mathrm{kWh}$ of electricity, reducing the annual carbon dioxide emissions by 495,376 kilograms. For the shopping mall, it was equipped with a $200 \mathrm{kw}$ solar energy independent power supply system, and also with smart meter monitoring and management to further achieve the goal of real energy saving and carbon reduction and resource reuse[3].

In the development of sustainable resources, the most difficult aspect for private enterprises at the implementation level is the overall planning, which not only need to avoid adding unnecessary burdens to the natural ecology, but more to expect to be able to feedback nature. The mall uses wind power and solar energy for independent power generation and it fully utilizes the water purification system with perfect water resources at the same time. Combined with the concept of natural symbiosis and sustainable development, the center effectively creates a smart environment control system such as temperature and humidity. The most energy-efficient environment and feedback was built, for the company's own image and value, even in the green recycling and resource reuse part of the perfection. For the region where the resources of the outlying islands are lacking, the necessity of resource reuse are more important.

\section{Conclusion}

The increase of carbon dioxide concentration caused by climate change has made "resource reuse" become the goal of global common development and resolution. How to reduce carbon dioxide emissions through effective resource utilization and resource recycling are gradually gaining importance also because of environmental awareness in all countries in the past decades. The whole world not only promote the global development of green buildings and the promotion of resource recycling, but also the implement public funds. The enterprises are also encouraged to uphold corporate social responsibility and encourage major enterprises to implement relevant policies.

In terms of "business philosophy", we must move towards a trend, and we can carry out groundbreaking architectural design, and improve the existing buildings to expand the ecological environment benefits, strengthen the promotion of its architects and more. The government's implementation of the construction system. For the corporate image, WIND LION PLAZA, through the concept of "sustainable management" and "sustainable recycling", hopes to use green building materials as an intermediary with local residents and enhance the interaction between enterprises and the people. It is to share its construction experience with local or other companies to understand and connect with the school, so that teachers and students can visit in order to understand the company's views on the implementation of green buildings. How does green building help the company's image and value? Compared with ordinary buildings, the construction of green buildings is more environmentally friendly. It allows more people to understand the difficulties faced by the current green building promotion and further enable the public to accept green. Buildings and enterprises can also give back to the society and fulfill their corporate social responsibilities. Moreover, WIND LION PLAZA also believe that through the green building and water resource as the main axis, on the one hand, they can fulfill their corporate social responsibilities, and the biggest benefit is that the corporate body can also greatly Ascension, and this part will increase with the interaction with the people. 
In Taiwan, we has an average annual rainfall of more than 2,500 $\mathrm{mm}$ compared to other countries. The amount of water allocated to each person is less than one-sixth of the global average, and the energy component is as high as $90 \%$ rely on overseas. With the reasons of people or land, it caused the ecological load to exceed the standard. In addition, there are more than 11 million metric tons of building materials waste generated each year, resulting in serious environmental pollution due to lack of recycling mechanism. For Jinmen County, which is located in the outer island, its impact is even worse. Even the basic water resources, because of the long-term lack of water in the topographical relationship, Jinmen also began to diverted water from Jinjiang, China on August 5, 2018. Inspiring private enterprises to be more active in promoting and implementing resource reuse is the government agencies in the future, and even the company responsibility itself. We should deeply think about those issues.

"WIND LION PLAZA " is an example case. In the process of construction, resource recycling has been incorporated into the core of the overall building. Through the cooperation between private enterprises and government agencies, and through the media, the public is more aware of the current global situation. The major environmental issues that we face together include promoting the conditions for sustainable coexistence with the environment, effectively reducing greenhouse gas emissions, and reducing environmental burdens. At the same time, we also promote "green DNA" in corporate culture and give employees awareness of environmental protection.

In the future development, how to promote the "reuse of resources" and let the people work together, and cooperate with government policies enable people and enterprises to effectively enhance the "circular" perception. The future damage and impact on the environment will be effective reduced. Furthermore, by enhancing its universal cognition, let more people understand the positive impact that "resource reuse" can bring to the environment. The "reuse of resources" will become more common in the future.

\section{Reference}

1. Hsu, C, Y.,The possible effects of global warming for the climate, typhoon, and ocean current in the future. Master's thesis (2009)

2. CWB, CWB annual report. CWB, Taipei (2018).

3. Wind Lion Plaza. Wind Lion Plaza Total carbon reduction. Kinmen (2019)

4. Chen, J.-M., J.-L. Chu, C.-F. Shih, and Y.-C. Tung. Interannua 